\title{
Analysis of Doppler Criteria in the Diagnosis of IUGR
}

\author{
Grif Caterina1, Rădulescu C1, Voidăzan S², Popa Carmen¹, Grama O1 \\ 1 Department of Obstetrics and Gynecology 2, University of Medicine and Pharmacy, Tîrgu Mureș, Romania \\ 2 Department of Epidemiology, University of Medicine and Pharmacy, Tîrgu Mureș, Romania
}

\begin{abstract}
Introduction: The assessment of the Doppler velocimetric indices of the uterine, umbilical and middle cerebral artery helps in diagnosing and monitoring pregnancies with fetal growth disorder.

Material and method: Two groups were studied: the $1^{\text {st }}$ group SGA (small for gestational age) including 22 fetuses whose birth weight was below the $10^{\text {th }}$ percentile for gestational age and the $2^{\text {nd }}$ group AGA (appropriate for gestational age) comprising 58 fetuses whose birth weight was between the $10^{\text {th }}$ and $90^{\text {th }}$ percentile. According to Doppler changes we could identify fetuses with intra uterine growth restriction (IUGR) and perform a comparative analysis of Doppler changes according to frequency and also assessed the predictive accuracy of some abnormal velocimetric indices for diagnosing SGA.

Results: In the SGA group we found 8 fetuses with IUGR (36.3\%), based on the fetal brain-sparing phenomenon indicated by Doppler changes. In the AGA group Doppler changes were observed in only 1 pregnancy (1.7\%). The frequency of Doppler changes was significantly higher in the SGA group. The highest predictive accuracy for SGA was found for a cerebroplacental ratio (CPR) below 1.08 (88.89\% PPV; 80.28\% NPV; $36.36 \%$ Se and $98.28 \%$ Sp) with $p<0.0001$.

Conclusions: Many cases of IUGR occur in pregnancies without evident risk factors as shown in this study. The most effective parameter for diagnosing SGA was found to be the CPR below 1.08 .
\end{abstract}

Keywords: IUGR, Doppler, velocimetric indices, cerebroplacental ratio

Received: 15 April 2011

\section{Introduction}

Although there are several definitions for a "small" fetus (small for gestational age - SGA), the specialty literature most commonly describes it as a fetus whose estimated weight is below the $10^{\text {th }}$ percentile for gestational age, in pregnancies without any maternal pathology and with normal Doppler of the umbilical and middle cerebral artery. Fetuses considered appropriate for gestational age (AGA) are those babies whose birth weight is between the $10^{\text {th }}$ and $90^{\text {th }}$ percentile for their gestational age [1-3]. Conversely, fetuses with real intrauterine growth restriction (IUGR) are SGA or even AGA fetuses with maternal pathology or abnormal brain or umbilical cord Doppler, recognized during pregnancy. When maternal pathology is absent, but there is an abnormal fetal velocimetry, small fetuses are defined as fetuses with "idiopathic" IUGR [4,5].

The purpose of this observational (case-control) study was to identify fetuses with late intrauterine growth restriction in the absence of an obvious etiological factor, to perform a comparative analysis of Doppler frequency changes in the two studied groups (to demonstrate the higher frequency of Doppler changes in pregnancies with SGA fetuses comparatively with pregnancies without fetal growth disorders) and to assess the predictive accuracy of some abnormal velocimetric indices to diagnose SGA.

\section{Material and method}

During 15 May 2008 - 16 July 2011, a prospective study

Correspondence to: Caterina Grif

E-mail: caterina_miladi@yahoo.com was performed on 80 cases of singleton fetuses in normotensive pregnancies and without an obvious etiological factor for fetal growth restriction. These cases were investigated and selected after examining 105 pregnant women in the third trimester and admitted to the Obstetrics and Gynecology Clinic No. 2, Tîrgu Mureş. Exclusion criteria were: twins, congenital malformations, chromosomal abnormalities and maternal pathology. Gestational age was determined after the last normal menstrual period and/or after the first trimester ultrasound.

The SGA group included 22 fetuses with their birth weight below the $10^{\text {th }}$ percentile according to local standards. The AGA group included 58 fetuses whose birth weight was between the $10^{\text {th }}$ and $90^{\text {th }}$ percentile for gestational age.

During the studied period, we used intrauterine growth curves for the correct assessment of fetal weight at birth according to gestational age at our clinic. We included in the statistical analysis data collected from 5088 alive newborn babies out of a total number of 5390 . The exclusion criteria comprised twins or multiple pregnancies, fetal abnormalities, dead fetuses and pregnancies with unclear information or without ultrasound examination in the first trimester. The $10^{\text {th }}, 50^{\text {th }}, 90^{\text {th }}$ percentiles were calculated, which allowed a proper classification of the 80 cases of singleton fetuses actually included in this study.

Doppler examinations were performed after a complete ultrasound investigation of the fetus with the pregnant woman placed in a recumbent or semirecumbent position. During the investigation we used a Logiq S6 (General Electric HealthCare 2006) ultrasound machine, equipped with 
Table I. $10^{\text {th }}, 50^{\text {th }}, 90^{\text {th }}$ percentiles of fetal weight at birth $(\mathrm{g})$ according to gestational age (week $-\mathrm{w}$ )

\begin{tabular}{|c|c|c|c|c|c|c|c|c|c|c|c|c|c|c|c|c|c|c|}
\hline \multirow[t]{2}{*}{ No. } & \multirow[t]{2}{*}{ Valid } & w 27 & 28 & 29 & 30 & 31 & 32 & 33 & 34 & 35 & 36 & 37 & 38 & 39 & 40 & 41 & 42 & 43 \\
\hline & & 2 & 1 & 3 & 4 & 6 & 20 & 29 & 53 & 111 & 179 & 329 & 890 & 1427 & 1687 & 328 & 18 & 1 \\
\hline \multirow{3}{*}{ 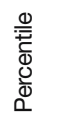 } & 10 & 900 & 900 & 900 & 1420 & 1400 & 1405 & 1570 & 1788 & 1892 & 2200 & 2350 & 2531 & 2738 & 2910 & 2999 & 2935 & 4670 \\
\hline & 50 & 920 & 900 & 1100 & 1475 & 1695 & 1670 & 1980 & 2120 & 2360 & 2600 & 2860 & 3070 & 3240 & 3440 & 3530 & 3465 & 4670 \\
\hline & 90 & 940 & 900 & 1270 & 1580 & 2250 & 2311 & 2500 & 2642 & 2988 & 3180 & 3400 & 3650 & 3830 & 4020 & 4202 & 4598 & 4670 \\
\hline
\end{tabular}

pulsed and color Doppler options. The high-pass filter was set at $70 \mathrm{~Hz}$ and the pulsed Doppler gate was chosen according to the diameter of the examined blood vessel. The fetuses were examined several times with ultrasound machine but prenatal Doppler ultrasound examinations were recorded by a single operator (G.C.) in the third trimester; however, only the final results of these examinations were used for the study. Both color and pulsed Doppler flow velocimetry of the uterine (especially placental uterine artery - PUA), umbilical arteries (UA) and the fetal middle cerebral artery (MCA) were performed in all cases. All spectral Doppler measurements were performed automatically from four or more consecutive waveforms, with the angle of insonation as close to 00 as possible, in the absence of fetal movements and if required, with voluntary suspended

Table II. Maternal and perinatal characteristics of the SGA and AGA groups

\begin{tabular}{|c|c|c|c|}
\hline Variable & & SGA $(N=22)$ & AGA $(N=58)$ \\
\hline Maternal age (years) & Average (SD) & $25.82(5.11)$ & $25.41(7.04)$ \\
\hline Area of origin (U/R) & $\%$ & $36.4 / 63.6$ & $44.8 / 55.2$ \\
\hline Studies & $\%$ & & \\
\hline Without & & 18.2 & 6.9 \\
\hline Primary & & 18.2 & 25.9 \\
\hline Secondary & & 45.4 & 46.5 \\
\hline Advanced & & 18.2 & 20.7 \\
\hline Smoking (yes/no) & $\%$ & $31.8 / 68.2$ & $20.7 / 79.3$ \\
\hline Socio-economic conditions & $\%$ & & \\
\hline Very poor & & 4.5 & 1.7 \\
\hline Poor & & 36.4 & 25.9 \\
\hline Average & & 18.2 & 22.4 \\
\hline Good & & 36.4 & 44.8 \\
\hline Very good & & 4.5 & 5.2 \\
\hline Maternal body mass index & Average (SD) & $27.02(4.06)$ & $26.77(3.81)$ \\
\hline Primiparous & $\%$ & 59.1 & 48.3 \\
\hline $\begin{array}{l}\text { Gestational age at delivery } \\
\text { (weeks) }\end{array}$ & Average (SD) & $39.68(1.17)$ & $39.17(1.71)$ \\
\hline MethoSD of delivery & $\%$ & & \\
\hline Spontaneous & & 50 & 37.9 \\
\hline Oxytocin perfusion & & 40.9 & 36.2 \\
\hline Cesarean section for fetuses & & 9.1 & 1.7 \\
\hline $\begin{array}{l}\text { Cesarean section (other } \\
\text { indications) }\end{array}$ & & 0 & 24.1 \\
\hline Birth weight $(g)(p<0.0001)^{*}$ & Average (SD) & $2561(339.7)$ & $3106(407.6)$ \\
\hline Male/female newborn & $\%$ & $59.1 / 40.9$ & $53.5 / 46.5$ \\
\hline 5-min Apgar score $(p=0.004)^{\star}$ & Average (SD) & $8.59(2.03)$ & $9.44(0.59)$ \\
\hline 5-min Apgar score $\leq 7$ & $\mathrm{Nr}$ & 1 & 0 \\
\hline Perinatal death & $\mathrm{Nr}$ & 1 & 0 \\
\hline
\end{tabular}

$\checkmark$ According to the National Institute of Statistics: average conditions - having the median salary per economy; poor - below the median salary per economy; very poor - without any salary; good - twice the median salary per economy; very good - more than twice the any salary; good - twice the median salary per
median salary per economy; ${ }^{*}$ Student test. maternal breathing. The spectrum of blood velocities in the examined arteries was analyzed especially for resistance index (RI) as a measure of vascular impedance. Values above the $95^{\text {th }}$ percentile according to gestational age for RI of the uterine and umbilical arteries were considered abnormal and values below the $5^{\text {th }}$ percentile for MCA RI were considered as sign of brain-sparing [6,7]. Additionally, the ratio between RI of the MCA and the RI of the umbilical artery was calculated. MCA RI/UA RI ratio (cerebroplacental-CPR ratio) lower than 1.08 was considered a sign of fetal circulation redistribution or brain-sparing [8,9]. In our study we diagnosed fetuses with real growth restriction according to these Doppler changes (IUGR).

Statistical analysis was performed using SPSS software 9th version, Graph Pad Demo and Graph Pad Prisma. Student's t-test and one-way analysis of variance were used for the comparison of mean values. A p value of $<0.05$ was considered significant; $\chi^{2}$ statistics or Fisher and $Z$ tests were used to compare proportions. Odds ratio (OR) with confidence intervals was also used for statistical analysis. Sensitivity (Se), specificity (Sp), positive (PPV) and negative (NPV) predictive values of the various blood flow velocimetry parameters were calculated in order to predict growth restriction.

\section{Results}

Table I presents the $10^{\text {th }}, 50^{\text {th }}, 90^{\text {th }}$ percentiles of fetal weight at birth $(\mathrm{g})$ according to gestational age (week $-\mathrm{w})$ in a preliminary study which allowed an adequate appreciation of SGA and AGA fetuses in our study.

Table II shows the maternal clinical and perinatal characteristics of the SGA and AGA group. Statistical analysis between the two groups identified significant differences

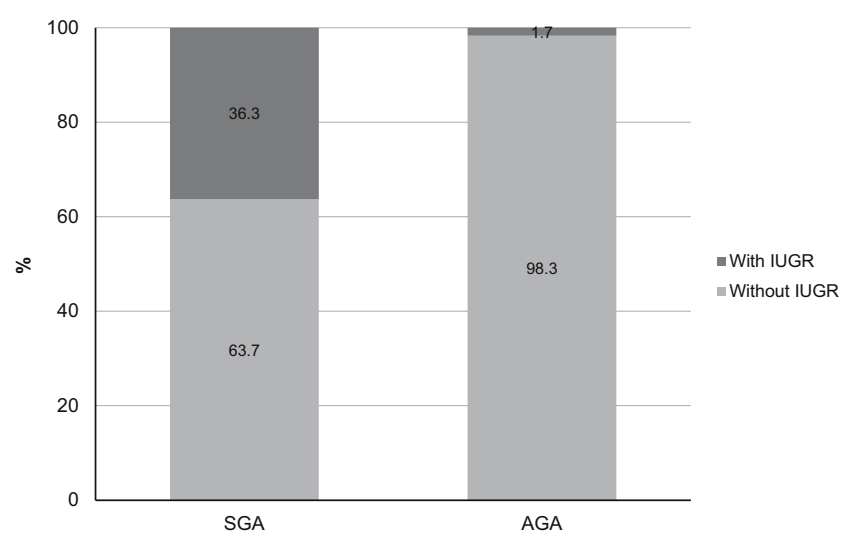

Fig. 1. Graphical representation of the proportion of IUGR in the studied groups 
Table III. Doppler frequency spectrum analysis in the studied groups

\begin{tabular}{lccccc}
\hline \multirow{2}{*}{ Abnormal indices } & \multicolumn{2}{c}{$\mathrm{SGA}(\mathrm{N}=22)$} & \multicolumn{2}{c}{ AGA $(\mathrm{N}=58)$} & \multirow{2}{*}{$\mathrm{p}$ value } \\
\cline { 2 - 5 } & $\mathrm{NR}$ & $\%$ & $\mathrm{NR}$ & $\%$ & \\
\hline $\mathrm{PUA} \mathrm{RI} \geq 95^{\text {th }}$ percentile & 8 & 36.36 & 5 & 8.62 & $0.007^{*}$ \\
$\mathrm{UA} \mathrm{RI} \geq 95^{\text {th }}$ percentile & 5 & 22.7 & 1 & 1.7 & $0.006^{*}$ \\
$\mathrm{MCA} \mathrm{RI} \leq 5^{\text {th }}$ percentile & 5 & 22.7 & 5 & 8.62 & $0.18^{*}$ \\
$\mathrm{CPR}<1.08$ & 8 & 36.36 & 1 & 1.7 & $0.0001^{*}$ \\
\hline
\end{tabular}

* $Z$ test

concerning fetal weight at birth and the Apgar score 5 minutes after birth.

In the SGA group we found 8 fetuses with IUGR, based on the fetal brain-sparing phenomenon indicated by Doppler changes (36.3\%). In the AGA group Doppler changes were observed in only 1 pregnancy $(1.7 \%)$. The graphical representation of the proportion of IUGR in the studied groups is shown in Figure 1.

"Idiopathic" placental insufficiency indicated by the dynamics of Doppler changes resulted in intrauterine fetal growth restriction (slowdown). The studied data entry in a contingency table demonstrated this kind of incidence by OR -32.571 ( $95 \%$ CI: 3.756 to 282.44 ), p value being $<0.0001$.

A comparative Doppler frequency spectrum analysis (abnormal indices appreciated according to reference values for the gestational age) in the 2 groups highlighted some significant differences that we represented in Table III. Predictive accuracy of abnormal Doppler indices for SGA diagnosis is depicted in Table IV.

\section{Discussions}

The two homogenous groups in this study (Table II) allowed a statistical analysis of some perinatal characteristics and the comparative analysis of Doppler frequency changes in the 2 groups, which proved to be more important.

The prenatal diagnosis of SGA fetuses was established relatively easily, based on serial ultrasound examinations including fetal biometry and on the assessment of fetal weight below the $10^{\text {th }}$ percentile according to gestational age.

The challenge was to identify fetuses presenting real intrauterine growth restriction by differentiating them from SGA fetuses, knowing that SGA fetuses are associated with a good prognosis compared to IUGR fetuses $[4,10]$.

The presence of IUGR in the AGA group could be explained by the fact that in some pregnancies there is a slow- down in the growth of the fetus, especially in the last trimester, which can be a deviation from the normal growth curve, which remains undetected because the birth weight is still above the $10^{\text {th }}$ percentile $[11,12]$.

A comparative Doppler frequency spectrum analysis (abnormal indices appreciated according to reference values of the gestational age) in the 2 groups revealed some significant differences (Table III, Figure 2). A similar proportion of cerebral Doppler changes in the 2 investigated groups explain the results of non-significant differences concerning MCA RI below the $5^{\text {th }}$ percentile. In case of some pregnancies we found the decrease of MCA RI in the absence of any umbilical Doppler changes, in both SGA and in AGA group. Although in our study we cannot prove it statistically, this case could have an explanation based on the placental insufficiency degree, which is not reflected by the umbilical Doppler frequency. Some more complex studies have already demonstrated the brain-sparing effect in pregnancies with normal umbilical Doppler and also revealed the adverse perinatal outcome with abnormal neurodevelopment fetuses presenting IUGR in these pregnancies [13].

Concerning the predictive accuracy of abnormal Doppler indices for the diagnosis of SGA, the specificity and a negative predictive value was above $90 \%$ and above $75 \%$ respectively similar for all indices. A greater positive predictive value was found for UA RI above the $95^{\text {th }}$ percentile and for a CPR less than 1.08 (Table IV). The predictive accuracy of CPR is comparable with that from other studies [14], but with a lower sensitivity. We chose the 1.08 value as a cut-off value for CPR, because CPR remained constant during the last 10 weeks of pregnancy [8] and the predictive value of a CPR below 1.08 for the adverse perinatal outcome was similar to the CPR value below the $5^{\text {th }}$ percentile for gestational age on the reference curves [15].

The superiority of CPR compared with other indices and evaluated separately in this study can be explained by the fact that CPR takes into account both the placental vascular anomaly, which was responsible for the altering of maternalfetal exchanges and cerebral hemodynamic response of the fetus to hypoxia $[2,16]$. Furthermore, evaluation by ratio might also prevent overestimation of occasional changes in blood flow in a single artery when the Doppler velocimetric indices of one artery are normal $[14,15]$.

\section{Conclusions}

Many cases of IUGR occur in pregnancies without evident risk factors as it was shown in this study. Therefore, ob-

Table IV. Predictive accuracy of abnormal Doppler indices for SGA diagnosis

\begin{tabular}{lcccrr}
\hline Abnormal indices & PPV (\%) & NPV (\%) & Se (\%) & Sp (\%) & P \\
\hline PUA RI $\geq 95^{\text {th }}$ percentile & 61.54 & 79.10 & 36.36 & 91.38 & 0.005 \\
UA RI $\geq 95^{\text {th }}$ percentile & 83.33 & 77.03 & 22.73 & 98.28 & 0.005 \\
MCA RI $\leq 5^{\text {th }}$ percentile & 50 & 75.71 & 22.73 & 91.38 & 0.12 \\
CPR $<1.08$ & 88.89 & 80.28 & 36.36 & 98.28 & $<0.0001$ \\
\hline
\end{tabular}

SGA - small-for-gestational age $\left(<10^{\text {th }}\right.$ percentile); PPV - positive predictive value; NPV - negative predictive value; Se - sensitivity; Sp - specificity; OR - odds ratio. 
stetricians should consider the possibility of fetal growth disturbance and implicitly fetal growth restriction in all pregnancies.

We identified more frequent Doppler changes in pregnancies with IUGR than in pregnancies without fetal growth disorders.

The most effective and accurate parameter was found to be the CPR below 1.08 which had Se, PPV, Sp, NPV values superior to other abnormal velocimetric indices separately evaluated for the diagnosis of fetal growth restriction.

Doppler changes allowed the identification of fetuses with intrauterine growth restriction, the consequence of a mild and progressive placental insufficiency, fact that has a more important role in monitoring pregnancy evolution than in taking a decision regarding delivery by caesarian section.

\section{References}

1. Rahimian J, Varner MW. Disproportionate Fetal Growth, in DeCherney AH, Nathan L, Goodwin TM, Laufer N (eds): Current Diagnosis \& Treatment in Obstetrics \& Gynecology. Medical Publishing Division McGraw-Hill Co. Inc. USA, International Edition 2006, 288-300.

2. Kahn BF, Hobbins JC, Galan HL. Intrauterine Growth Restriction in Gibbs RS, Karlan BY, Haney AF, Nygaard IE (eds): Danforth's Obstetrics and Gynecology. Lippincott Williams \& Wilkins Publishers, Philadelphia, PA, 2008, 198-219.

3. Cunningham FG, Leveno KJ, Bloom SL et al. Williams Obstetrics 23st Ed by The McGraw-Hill Companies, Inc. Medical Publishing Division, USA, 2010, 843-852.

4. Mari $G$, Hanif $F$. Intrauterine growth restriction: how to manage and when to deliver. Clin Obstet Gynecol. 2007;50:497-509.

5. Cosmi E, Ambrosini G, D'Antona D, Saccardi C, Mari G. Doppler, cardiotocography, and biophysical profile changes in growth-restricted fetuses. Obstet Gynecol. 2005;106(6):1240-1245.

6. Kurmanavicius J, Florio I, Wisser $\mathrm{J}$ et al. Reference resistance indices of the umbilical, fetal middle cerebral and uterine arteries at 24-42 weeks of gestation. Ultrasound Obstet Gynecol. 1997;10:112-120.

7. Acharya G, Wilsqaard T, Berntsen KR, Maltau JM, Kiserud T. Reference ranges for serial measurements of umbilical artery Doppler indices in the second half of pregnancy. Am J Obstet Gynecol. 2005;192:937-944.

8. Gramellini D, Folli MC, Raboni S, Vadora E, Merialdi A. Cerebral-umbilical Doppler ratio as a predictor of adverse perinatal outcome. Obstet Gynecol 1992; 79:416-420.

9. Baschat AA, Gembruch U. The cerebroplacental Doppler ratio revised. Ultrasound Obstet Gynecol. 2003;21:124-127.

10. Dashe JS, Mclntire DD, Lucas MJ, Leveno KJ. Effects of symmetric and asymmetric fetal growth on pregnancy outcomes. Obstetrics and Gynecology. 2000;96(3):321-327.

11. Marconi AM, Ronzoni S, Bozzetti P et al. Comparison of fetal and neonatal growth curves in detecting growth restriction. Obstet Gynecol. 2008;112: 1227-1234.

12. Bamfo JE, Odibo AO. Diagnosis and Management of Fetal Growth Restriction. J Pregnancy. 2011;2011:640-715.

13. Figueras F, Eixarch E, Meler E et al. Small-for-gestational-age fetuses with normal umbilical artery Doppler have suboptimal perinatal and neurodevelopmental outcome. Eur J Obstet Gynecol Reprod Biol. 2008;136(1):34-38.

14. Simanaviciute D, Gudmundsson S. Fetal middle cerebral to uterine artery pulsatility index ratios in normal and pre-eclamptic pregnancies. Ultrasound Obstet Gynecol. 2006;28:794-801.

15. Odibo AO, Riddick C, Pare E, Stamilio DM, Macones GA. Cerebroplacental Doppler ratio and adverse perinatal outcomes in intrauterine growth restriction: evaluating the impact of using gestational age-specific reference values. J Ultrasound Med. 2005;24:1223-1228.

16. Mihu D. Examenul ecografic Doppler în trimestrele II și III de sarcină, în Mihu D (ed): Ecografia Doppler în obstetrică și ginecologie. Editura Clusium, Cluj-Napoca, 2001, 78-214. 